\title{
The Application of PBL and TBL in Nursing English Teaching
}

\author{
Lei Li \\ Foreign Language School, Henan University of Chinese Medicine, No. 1 of Jinshuidong Road, \\ Zhengzhou, Henan Province, China \\ zelda_2002cn@163.com
}

\section{Keywords: PBL; TBL; Nursing English Teaching}

\begin{abstract}
Problem-based learning (PBL) and task-based Learning (TBL) can both be applied to the teaching of nursing English to encourage and guide students' self-learning abilities. Teachers should design teaching tasks and carry out teaching activities based on actual situations, make a timely evaluation and summary of the students' stages of learning, enrich the teaching form and content, and enhance the teaching effect.
\end{abstract}

\section{Introduction}

Since the 1980s, many domestic medical schools have provided international nursing programs. Compared to nursing professional skills, the cultivation of practical application ability of nursing English is the key point and difficulty. Despite the similarities with medical English, nursing English puts more emphasis on the improvement of oral communication and written expression skills in practical work. The teaching concept and method of cramming, emphasis on input and neglect of output cannot satisfy students' demand of improving comprehensive application abilities. Traditional single teaching mode can no longer satisfy the teaching demand in the multi-media environment of the new era. Therefore, it is necessary to adopt the multi-mode three-dimensional teaching mode, including Situational Language Teaching (SLT), Problem-based Learning (PBL) and Task-based Learning (TBL). Su Huifen \& You Guilan pointed our that: conforming to the new trend of internationalization of the need of English nursing professional personnel, teaching contents will need to reflect the characteristics of new age. Firstly, the conception of teaching and learning should be of temporal spirit. Combined with cultural education, students' comprehensive competence should be the focus in cultivation. Teaching methodology should be of innovation. In the process of nursing English teaching, teachers should try to improve the evaluating methods and make good use of public media and Internet information in order to cultivate out nursing persons with compound ability who adapt to the new situation in China and in the internation[1].

\section{PBL and TBL Teaching Method}

PBL Teaching Method. PBL (Problem-based Learning) originated from the medical education in the 1950s. The main content is designing learning situations and carrying out problem-oriented teaching. It emphasizes the active learning of students, sets complex and meaningful problem scenarios to guide learners to explore autonomously and cooperate to solve problems. Its essence is the guidance of the problem on the learning process, which can mobilize the initiative and enthusiasm of students. Specific teaching ideas include: teachers ask questions before class - students find information - group discussion - teachers' summary. PBL pedagogy is an interdisciplinary learning method, which can promote students to think and solve problems, develop their self-learning spirit, highlight the teaching philosophy of "classroom is the soul, students taken as the main body and the teacher regarded as the key". In PBL teaching, teachers only play the role of directing, scaffolding and coaching. They are no longer taken as the only knowledge base, but facilitators of knowledge construction, experts, and consultants of information.

PBL has many advantages: creating a relaxed learning atmosphere for students to speak freely; exposing problems in the curriculum as much as possible; deepening understanding in the discussion, 
discovering and answering questions, shortening learning process, deepening the impression; being beneficial to the theoretical study, and cultivating students' abilities of literature search, induction and summary, logical reasoning, oral expression, self-learning and lifelong learning, etc. PBL teaching mode emphasizes students' self-inquiry, focuses on the process of inquiring and solving problems and stresses the cultivation of students' abilities. Nowadays, college English teaching has been divided into varied fields of academic English teaching. Through the application of PBL, students could make great improvements in autonomous learning, critical thinking cultivation, literature search, information search and exchange, English presentations in the classroom, etc. But there are still many difficulties and obstacles in the teaching process, including different English levels of students, knowledge structures of teachers and teaching environments, etc.

TBL Teaching Method. TBL means Team-based Learning or task-based learning, which is associated with TBLT (Task-Based Language Teaching). Its main contents include: advocating task-based teaching methods, training students' comprehensive application abilities. Teachers should avoid simply imparting knowledge, design practical teaching activities according to the curriculum objectives and teaching contents, attract and organize students to actively participate. Students learn and use knowledge by thinking, investigating, discussing, communicating, and collaborating. Teachers should pay attention to the following aspects: the purpose of the activities should be clear and operational; students' life experiences and interests should be taken as a starting point, contents and methods being as real as possible; activities should contribute to the development of learning and skills of students and the improvement of practical application abilities; activities should actively promote the interdisciplinary penetration and connection, so that the overall quality of students can be developed; activities should enable students to acquire, process and use information to communicate with others, develop their abilities of solving practical problems; activities should not be limited to the classroom, but also extended to the extracurricular activities.

TBL emphasizes "learning by using and learning by doing", advocates students' participations and interactions in classroom and is adopted to improve students' communicative competence. It can be traced from and is strongly influenced by Communicative Language Teaching. Besides, constructivism and social interaction theory also have great influence on it. TBL mainly stresses the importance that learners bring to the learning surrounding as an energetic problem-solver and meaning-maker. As a result, the learner takes the leading role in language class. The interactive communication between students, teachers and tasks has the dynamic peculiarity that is the importance of social interaction that also proves the idea that learning stems from interactions ${ }^{[2]}$.

\section{Nursing English Teaching}

Nursing English teaching has been developed more or less, but it is still not perfect. In order to search for feasible and effective ways in nursing English teaching, educators and linguistic researchers made investigations on different aspects, including learners' learning motivation, learning strategies, learning situation and teaching methods. According to the survey on the demand of nursing English among nurses in six top-grade medical institutions in China, setting goals for nursing English courses should pay special attention to students' application abilities, including listening, speaking, reading and writing aspects. Teaching textbooks should put emphasis on the knowledge, special terms and communication skills of the nursing subject. Teaching methods of nursing English should adopt the situational teaching mode of nursing English in hospitals. Nursing English teaching should adopt different teaching methods to build up students' knowledge structure, learn about language features of nursing English and medical terms.

Teaching Methods. At present, teaching with grammar and translation is the main teaching method of nursing English, mainly manifested as follows: teachers are taken as the center of the classroom; pronunciation, grammar and vocabulary teachings are interconnected, with reading and translation as the leading part, listening and speaking as the rest; grammar is taken as the main teaching content, using the mother tongue as the tool. The shortcomings of this kind of teaching are obvious. Only paying attention to reading, translation and grammar, relying on the mother tongue too much, emphasizing the 
knowledge impartment, ignoring the cultivation of language skills and oral teaching, separating the teaching of pronunciation, vocabulary, grammar and the text, translating sentence by sentence from paragraph to paragraph would cause the teaching atmosphere tedious and dull. The application of communicative approach in nursing English teaching include: providing real linguistic data, adopting typical communicative activities, playing roles, such as registration, medical consultation, drawing blood, dispensing, medical imaging and intravenous injection, etc. Simulation activities and group discussions are also adopted.

Knowledge Structure. The results of a questionnaire show that students' learning motivation includes both internal and external causes (interests vs. long-term and short-term needs). Learning objectives include finding a job in future, engaging in foreign nursing work after graduation and using English to communicate. Besides injection, dispensary and taking temperature, nurses should also get to know the medical condition, feelings, emotions, family and environment of the patient, make nursing diagnosis and plan, and provide a nursing scheme to help patients recover physically and mentally. They should also learn to communicate orally, write nursing record and shift record in English, read instructions and get to know the International nursing licensure examinations. Besides, as a part of the case report, nursing record has a legal effect and belongs to the formal style. Oral nursing English belongs to the informal style. Both of them are fundamental knowledge for nurses. PBL helps students find out problems and then solve them under the guidance of teachers. Firstly, they should find out the reason of learning and contents of learning. Then they are asked to make a specific plan during the learning process. After learning the course, they should establish a comprehensive knowledge structure and become skillful in using nursing English in daily work and future study.

Language Features. Oral nursing English is usually composed of common general English words, such as heart attack, stroke and rapid heartbeat, etc. Sentence structures are often scattered (such as sentence fragments or abbreviated sentences), which should be understood according to the context. Euphemisms are often used, such as "The patient is not doing well". Vague sentences are often used, such as "I'm afraid.../It seems..." Written nursing English belongs to the formal style, which should be standard in expressions, with proper use of abbreviations and symbols, such as c/o (complains of). Sentences are usually short, with specific meanings and omitted subjects. They should record time correctly, describe objectively and specifically, choose correct words and sign names after each record. No space is allowed in the record. Mistakes should not be obliterated. Instead, nurses should cross it over by a line, write the word "error" on it and then sign their names. Nursing English is a part of medical English, but pays special attention of nursing knowledge. When students are learning about language features, they could adopt TBL to pursue different stages of learning objectives. Teachers serve as guides during the process, timely answer students' questions and help them solve problems during the task fulfillment.

Medical Terms. Nursing English teaching inevitably involves common medical words, which is divided into three types: 1) General words with specific medical meanings, such as labor, culture, colon and murmur, etc; 2) Special terms with combined medical morphemes, such as hypertension, gastritis, "gastro-" and "-ectomy"; 3) Exclusive medical terms, such as nausea and vomiting, etc. Besides, common abbreviations are also included in the teaching contents, such as "n. p. o (Nothing by mouth) and t. i. d. (Three times a day)".[3] Based on TBL method, teachers assign the task of classifying medical words in the textbook after each class, and ask students to report their assignments. Through comparison and analysis, students could learn new words and expressions much better based on their preceding vocabulary knowledge.

\section{Case study: Nursing English Teaching in Henan University of TCM}

The nursing English course currently offered in Henan University of TCM mainly includes optional courses for juniors of the nursing major and compulsory courses for sophomores of nursing English majors and nursing health English majors. The chosen teaching material is Nursing English published by China Ocean University Press, which is compiled by teachers from many nursing colleges and universities throughout China. The contents of the textbook are chosen from original English books or 
foreign websites, including all aspects of medicine and nursing career. Each unit is composed of listening training, dialogues and theme reading, with audios and videos attached. Many extended exercises are attached after each text, which can effectively improve students' application abilities of English. Medical English terminology is also included in every unit. The appendix is also very practical.

Teaching contents include: the development of nursing, outpatient service, admission, emergency nursing, internal medical nursing, surgical nursing, pediatric nursing, obstetric and gynecologic care, psychiatric nursing, geriatric nursing, rehabilitation nursing, medical imaging, discharge, nursing records, community health nursing, nursing education and training abroad, etc. Before each lecture, teachers would help students find main tasks for them to fulfill, guide them to get familiar with each topic, and check their assignments in the following class. Except texts, teaching materials also include audios, videos and on-line extended resources, which include plenty of electronic books, pictures, audios and videos, etc. Medical films and TV programs, such as ER, Grey's Anatomy and Nurse Betty, can also be used as extended teaching materials. [4] Among these abundant teaching materials, students' tasks are still centered on what they've learned in the class.

The course uses a comprehensive evaluation method, including formative assessment (40 points) and summative assessment (60 points). Among them, formative assessment includes: classroom performance and attendance (20 points), oral report (10 points), and written homework (10 points). The specific course design is as follows: choose one subject to make a speech every class and guide students to discuss in groups and give oral presentations in different stages. The form and content of presentations are not strictly limited, but are all related to medical English. Written assignments are associated with the contents of the subject, arranged in the beginning of the term and handed in at the end of the term. Through the comprehensive application of PBL and TBL, students' initiative has been improved greatly and the teaching effects have been promoted significantly, which are manifested as a variety of oral presentations of students.

Based on TBL and PBL, students' presentations are divided into several types: 1) Role-play. Use white coat, stethoscope, needle, gloves and other props to dub for the medical drama, or imitate the nursing English dialogue in the real context, such as registration, consultation or nurse-patient dialogues. 2) Specific topics. Choose specific topics, such as colorful nurse uniform, borderless nurses, male nurses, career promotion of nurses, nurse-patient communication, medical drama, medical museum, euthanasia and other topics. 3) Nursing methods. In-depth explanations of nursing process for sub-health group, cold, peptic ulcer, liver cirrhosis, HIV virus and AIDS, diabetes, hypertension, pregnant women, premature children, neonatal, hospice, emergency patients and disabled people; demonstration of practical operational methods for intravenous injection, disinfection, cardiopulmonary resuscitation or CT.

Role playing is a practice for learners to communicate with other people, discover emotions involved in various behaviors, and practice new behaviors and attitudes in a safe situation that resembles real conditions. It assists students to enhance their own understandings and others' feelings, develop new behaviors, and improve their problem solving skills. It's a good way to help students show values, feelings, attitudes and solutions and finally listen to their teacher's evaluations. Besides lectures, e-learning and role playing serve as effective means for teachers to facilitate students' independent learning [5]. Blended learning is a good way to apply different methods, strategies, techniques and medias in education. Today, due to the development of the infrastructure of Internet networks and the access of most of students, the Internet can be utilized along with traditional and conventional methods of training. E-learning is a supplement to traditional teaching methods, sometimes used as an alternative educational method because this teaching method can increase students' knowledge, satisfaction and attention.

Lecture is the most common teaching form, which is simple, fast and cheap to present vast issues to lots of learners. Its disadvantages include: inactiveness of students, tiring long contents, one-way communication, and fast forgetting. Blended teaching methods are adopted to change the situation. Except traditional lecturing method, other teaching methods are also used, such as multimedia courses, seminars and e-learning. Face-to-face communications are combined with flexible e-learning. Though 
e-learning is a good supplement to traditional teaching methods, it also has its own weaknesses. It cannot replace the teacher and the human interaction and communication in face-to-face classroom.[6]

\section{Conclusion}

Under the rapidly developing multimedia teaching environment, using teaching methods comprehensively, enriching and improving teaching forms and contents can guide students to carry out problem-oriented and task-oriented group discussions and self-learning research. During the problem solution and task completion, abilities of analyzing and solving problems can be improved. Students are guided to participate in teaching abilities actively to improve learning efficiency. Teachers should try to guide, evaluate and summarize, improve the level of education and teaching, integrate the professional education with general liberal education and promote the overall development of students.

\section{Acknowledgements}

This article is result of Henan Planning Project of Philosophy and Social Sciences "Integration of Foreign Language Teaching Resources based on the Internet of Things" (No. 2015BYY017), General Research Project of Humanities and Social Sciences "Research on the Competence Cultivation of Communications with TCM English" (No. 2015-ZD-217) approved by Henan Education Department, and Henan Soft Science Project "Corpus-based diachronic study of cultural term translation in English translation versions of Huangdi Neijing” (No. 152400410137).

\section{References}

[1] H.F. Su, G. L. You: New Trends of Nursing English Teaching in English Nursing Major, Nanfang Journal of Nursing, Vol. 06 (2005), p. 67-69. (In Chinese)

[2] J. Zhang: The Experimental Study on Task-based Nursing English Teaching in Higher Vocational College, (MS., Hebei Normal University, China 2012), p. 2-16. (In Chinese)

[3] H.M. Zhu: Study on Teaching Methods of English for Nurses, (MS., Central China Normal University, China 2007), p. 10-13. (In Chinese)

[4] J.F. Zhu, H. Xue: Nursing English, 1st ed., (China Ocean University Press, China 2013). (In Chinese)

[5] T. Pourghaznein, H. Sabeghi and K. Shariatinejad: Effects of E-learning, Lectures, and Role Playing on Nursing Students' Knowledge Acquisition, Retention and Satisfaction, Medical Journal of the Islamic Republic of Iran, Vol. 29 (2015), p. 162.

[6] R. Sadeghi, M. Sedaghat and F. Ahmadi: Comparison of the Effect of Lecture and Blended Teaching Methods on Students' Learning and Satisfaction, Journal of Advances in Medical Education \& Professionalism, Vol. 08 (2014), p. 146-150. 